East African Medical Journal Vol. 85 No. 3 March 2009

ANTI-DIABETIC DRUGS IN THE PRIVATE AND PUBLIC SECTOR IN DAR ES SALAAM, TANZANIA

M. Justin-Temu, B.Pharm, M.Pharm, PhD, Department of Pharmaceutics, School of Pharmacy, R.S. O. Nondo, B.Pharm, Department of Pharmacology, Institute of Traditional Medicine, Muhimbili University of Health and Allied Sciences, P.O. Box 65013, Dar es Salaam, Tanzania, K. Wiedenmayer, MSc, PharmD, Swiss Tropical Institute, Socinstrasse 57, 4002 Basel, Switzerland, K. L. Ramaiya, MBBS, MMed (Int.Med) Consultant Physician, Shre, Hindu Mandal Hospital, P.O. Box 581, Dar es Salaam, Tanzania and A. Teuscher MD, PhD, Nutrition and Diabetes Foundation, Beaulieustrasse 88, 3012 Bern, Switzerland

Request for reprints to: Dr. M. Justin-Temu, Department of Pharmaceutics, School of Pharmacy, Muhimbili University of Health and Allied Sciences, P.O.Box 65013, Dar es Salaam, Tanzania

\title{
ANTI-DIABETIC DRUGS IN THE PRIVATE AND PUBLIC SECTOR IN DAR ES SALAAM, TANZANIA
}

\author{
M. JUSTIN-TEMU, R. S. O. NONDO, K. WIEDENMAYER, K. L. RAMAIYA and A. TEUSCHER
}

\begin{abstract}
Objectives: To compare availability, cost, affordability and sources of anti-diabetic drugs between private and public health facilities in Dar es Salaam, Tanzania.

Design: Cross sectional descriptive study.

Setting: Diabetic clinics in private and public health facilities in Dar es Salaam, Tanzania.

Subjects: Eighty patients randomly selected and 45 health facility personnel staff working in the diabetic clinics. Semi-structured questionnaires and a checklist were used to collect the information.

Results: Oral hypoglycaemic agents were available in all seven private and three public facilities that were studied. Private facilities stocked more types of oral hypoglycaemic agents than public facilities, which stocked only chlorpropamide and tolbutamide, based on the National Essential Drugs List. The cost of chlorpropamide was five times higher in private facilities compared to public facilities. Insulin was also available in all the facilities. The price of animal insulin in private health facilities was ten times that in public health facilities. Human insulin, which is generally more expensive than animal insulin, was only available in private facilities. Although prices were much lower in public facilities, affordability emerged as a common issue in both private and public facilities.

Conclusions: Urban private health facilities offer a wider choice for the needs of diabetic patients but this advantage is compromised by higher prices as compared to public facilities as well as inconsistent supply across facilities. Public health facilities offer only a limited selection of essential oral hypoglycaemics and insulin but at a lower price and across all facilities. Twenty six per cent and $10 \%$ of patients in public and private facilities respectively are unable to afford anti-diabetic drugs. The need for intervention to increase affordability of anti-diabetic drugs is evident. Financing and cost of drugs needs to be addressed, either by means of health insurance or other mechanisms, in this era of increasing prevalence of diabetes mellitus among developing countries.
\end{abstract}

\section{INTRODUCTION}

In 2003, the prevalence of diabetes for all age groups worldwide was estimated at $5.1 \%$. The number of deaths attributed to diabetes worldwide was estimated to be 1.1 million in 2005 (1). Globally in the year 2003 the number of people with diabetes was estimated to be 194 million. The World Health Organisation (WHO) and the International Diabetes Federation (IDF) project that the number of diabetic patients may double by the year 2030, and suggest the need to prepare national health services for the projected increase. Almost $80 \%$ of deaths related to diabetes occur in 
low and middle income countries (1). Although diabetes is sometimes considered a condition of developed nations, the loss of life from premature death among persons with diabetes is greatest in developing countries.

The prevalence of type 1 and type 2 diabetes in African countries (urban and rural) varies considerably, but it was estimated to be in the dimension of 0.01-1.0\% in Tanzania in 1996 (2). The percentages of all deaths associated with diabetes in Dar es Salaam were estimated to be $2.6 \%$ for males and $1.7 \%$ for females (2). The estimated number of diabetics in Tanzania in 2000 was 201,000 and based on about $6.7 \%$ annual growth rate, it is projected that the number will rise to 605,000 in 2030.

A recent survey revealed that only $3 \%$ of people with diabetes in developing countries are treated with anti-diabetic drugs, as compared to $13 \%$ in the developed world. The reasons are complex, ranging from culturally based misconceptions to chronic shortages of drugs which may be due to lack of finance in the health sector, poor procurement or ineffective distribution and inadequate storage (3). Access to drugs can be defined as availability, geographical accessibility, affordability (ability to pay) and cultural acceptability.

Drugs are the mainstay of diabetes treatment, therefore they need to be available, easily accessible, affordable and culturally suitable to diabetic patients who need treatment throughout their lives (4). The cost of diabetes affect all patients everywhere and not only include financial difficulties. Intangible costs such as pain, anxiety, inconvenience and generally lower quality of life also have great impact on the lives of patients and their families and are the most difficult to quantify (5). Insulin is a costly medication and is unavailable or unaffordable in many poor countries, despite being listed by $\mathrm{WHO}$ as an essential drug (1). The price of insulin without syringe, need and necessary equipment for monitoring blood glucose levels varies widely from country to country, ranging from less than US\$ 3 to US\$ 45 a vial. However, in many African countries the cost of a vial of insulin may be the equivalent of a month's salary (1). In Tanzania, with cost-sharing schemes in the public health sector, the cost of one vial of animal insulin is about US\$1 (6). Diabetes and its complicationsimpose significant economic consequences on individuals, families, health systems and countries (1).

Government health facilities in Tanzania buy drugs based on the National Essential Drugs List including anti-diabetic drugs from the Medical Stores Department. Patients currently get drugs from government health facilities under a cost-sharing scheme whereby they are required to pay $50 \%$ of the actual price of the drugs (6). Private health facilities do not purchase their medicines from MSD; instead they purchase from private wholesale, retail pharmacies and other sources of drug supply. This removes monopoly and allows more drugs to be available, but there are significant differences in terms of availability and cost of drugs between the two sectors. In the private sectors patients are required to pay the full cost of the drugs out of pocket. All drugs on the local market have to be registered by the Tanzanian Food and Drug Authority.

\section{MATERIALS AND METHODS}

Study population: The survey was conducted in the three district hospital facilities in Dar es Salaam city namely Amana (Ilala), Temeke and Mwananyamala (Kinondoni) in the public sector, and in seven randomly selected private facilities, two hospitals and five health centres in 2003 . The study involved 80 patients attending diabetes clinics, both in public and private sectors and 45 staff in-charge of the clinics and pharmacists / pharmaceutical technicians responsible for handling anti-diabetic drugs.

Data collection: Face to face interviews using semistructured open and closed ended questionnaires were used to collect information from patients, medical officers in charge of diabetes clinics and pharmacists / pharmaceutical assistants responsibleforhandling and dispensing hypoglycaemic agents both in public and private health facilities. Drug records were viewed, checked on reliability and compared to the information given by respondents. All subjects wereinformed about the contents of the interview and aims of the study before participation. They were also asked for consent to participate in the study to guarantee voluntary participation, assured anonymity, confidentiality and were given opportunity to comment on what they had been asked during the interview. Study questions included availability, cost, affordability and sources of anti-diabetic drugs.

\section{RESULTS}

The mean number of 23 diabetic patients who attended private facilities was lower than 106 who attended in public facilities during the study period. Nineteen patients attending private facilities and 61 patients attending public health facilities were interviewed. Eighty three of patients attending private facilities were type 2 diabetic patients and $17 \%$ were type 1 patients. More patients from both private and public health facilities use oral hypoglycaemic agents than insulin injections. In private facilities about 53\% use oral hypoglycaemics compared to $59 \%$ in public hospitals. In private facilities $42 \%$ of patients use insulin injections, while $38 \%$ of patients in public facilities use insulin (Table 1). 
The survey showed that both insulin and oral hypoglycaemic agents were availablein all private and public facilities. Seven types of oral hypoglycaemic agents were found in private facilities as compared to two types in public facilities; chlorpropamide and tolbutamide. Both private and public facilities provided insulin, but human insulin was only available in three out of seven (43\%) private health facilities while none of the public heath facilities had human type of insulin (Table 3).

The main sources of anti-diabetic drugs in private facilities were wholesale pharmacies $(57 \%)$ and retail pharmacies $(43 \%)$, while public health facilities received their drugs from the medical stores department.

The mean price of animal Actrapid insulin in private facilities was US $\$ 5.45$ per vial while in public facilities the mean cost for the same drug was US $\$ 0.55$. In the private facilities animal Lente insulin was sold at a mean price of US\$ 5.60 while in public facilities it was sold at a price of US\$ 0.55 . Chlorpropamide at $250 \mathrm{mg}$ tablet was sold at US\$ 0.09 per tablet in private facilities while in public facilities the mean price was US $\$ 0.02$ (Table 4).

Table 1

Types of anti-diabetic drugs used by patients in three public and seven private facilities

\begin{tabular}{lcccc}
\hline \multirow{2}{*}{ Type of drug } & \multicolumn{5}{c}{ Number of patients } \\
& Private facilities & $(\%)$ & Public facilities & $(\%)$ \\
\hline Insulin & 8 & 42.1 & 23 & 38 \\
Oral hypoglycaemics & 10 & 52.6 & 36 & 59 \\
Both insulin and oral hypoglycaemics & 1 & 5.3 & 2 & 3 \\
\hline Total & 19 & 100 & 61 & 100 \\
\hline
\end{tabular}

Table 2

Patients' responses pertaining to availability of anti-diabetic drugs in private and public facilities

\begin{tabular}{lcccc}
\hline Availability & \multicolumn{4}{c}{ Number of patients } \\
& Private facilities & $(\%)$ & Public facilities & $(\%)$ \\
\hline Always available & 17 & 89.5 & 32 & 52.4 \\
Seldom available & 2 & 10.5 & 25 & 41.0 \\
Not available at all & 0 & 0 & 4 & 6.6 \\
\hline Total & 19 & 100 & 61 & 100 \\
\hline
\end{tabular}

Table 3

Anti-diabetic drugs available in private and public facilities

\begin{tabular}{lcccc}
\hline Type of drug & \multicolumn{5}{c}{ Health facility } \\
& Private $(\mathrm{n}=7)$ & $(\%)$ & Public $(\mathrm{n}=3)$ & $(\%)$ \\
\hline Insulin & 7 & 100 & 3 & 100 \\
$\quad$ Animal & 3 & 42.9 & - & 0 \\
$\quad$ Human & & & & \\
Oral drugs & 3 & 42.9 & - & 0 \\
$\quad$ Acarbose & 6 & 85.7 & 3 & 100 \\
Chlorpropamide & 5 & 71.4 & - & 0 \\
Glibenclamide 5mg & 3 & 42.9 & - & 0 \\
Gliclazide 80mg & 5 & 71.4 & - & 0 \\
$\quad$ Glipizide 5mg & 7 & 100 & - & 0 \\
$\quad$ Metformin 500mg & 1 & 14.3 & 3 & 100 \\
$\quad$ Tolbutamide 500mg & & &
\end{tabular}


Table 4

Costs of anti-diabetic drugs in private and public health facilities (US\$ per tablet or vial)

\begin{tabular}{|c|c|c|c|c|c|c|}
\hline \multirow[t]{2}{*}{ Type of Drug } & \multicolumn{3}{|c|}{$\begin{array}{l}\text { Cost of drugs in } \\
\text { private health facilities } \\
\text { Mean }\end{array}$} & \multicolumn{3}{|c|}{$\begin{array}{l}\text { Cost of drugs in } \\
\text { public health facilities } \\
\text { Mean }\end{array}$} \\
\hline & $\begin{array}{l}\text { Mean } \\
\text { price }\end{array}$ & Min & Max & $\begin{array}{l}\text { Mean } \\
\text { price }\end{array}$ & Min & Max \\
\hline \multicolumn{7}{|l|}{ Insulin } \\
\hline Pork Actrapid 30/70 $40 \mathrm{IU} /$ units & 5.45 & 3 & 8.50 & 0.55 & 0.50 & 0.65 \\
\hline Pork Lente $40 \mathrm{IU} /$ units & 5.60 & 3 & 8.50 & 0.55 & 0.50 & 0.65 \\
\hline Human mixtard $30 / 70100 \mathrm{IU} /$ units & 24.80 & 24.80 & 24.80 & - & - & - \\
\hline Humulin 30/70 $100 \mathrm{IU} /$ units & 30.00 & 30.00 & 30.00 & - & - & - \\
\hline Humulin regular $100 \mathrm{IU} /$ units & 36.00 & 36.00 & 36.00 & - & - & - \\
\hline \multicolumn{7}{|l|}{ Oral drugs } \\
\hline Acarbose $50 \mathrm{mg}$ & 0.35 & 0.35 & 0.35 & - & - & - \\
\hline Chlorpropamide $250 \mathrm{mg}$ & 0.094 & 0.05 & 0.10 & 0.019 & 0.017 & 0.02 \\
\hline Glibenclamide 5mg & 0.0275 & 0.02 & 0.05 & - & - & - \\
\hline Gliclazide 80mg & 0.223 & 0.03 & 0.145 & - & - & - \\
\hline Glipizide 5mg & 0.082 & 0.05 & 0.1 & - & - & - \\
\hline Metformin 500mg & 0.087 & 0.015 & 0.10 & - & - & - \\
\hline Tolbutamide $500 \mathrm{mg}$ & - & - & - & 0.019 & 0.017 & 0.02 \\
\hline
\end{tabular}

Table 5

Affordability of anti-diabetic drugs in three private and seven public health facilities

\begin{tabular}{lcccc}
\hline Affordability & \multicolumn{3}{c}{ Number of patients } \\
& Private facilities & $(\%)$ & Public facilities & $(\%)$ \\
\hline Able to pay & 17 & 89.5 & 45 & 73.8 \\
Unable to pay & 2 & 10.5 & 16 & 26.2 \\
\hline Total & 19 & 100 & 61 & 100 \\
\hline
\end{tabular}

Responses by pharmacists/pharmaceutical technicians revealed that there were no complaints from patients in private facilities about availability of anti-diabetic drugs. In private facilities the cost of drugs was the most common complaint, and affordability came up as an issue in four facilities. On the other hand, in all three public facilities, the most common complaint was non-availability of medicines. No complaints about the cost and affordability of drugs were observed in public facilities.

From a patient point of view, $90 \%$ of patients indicated that anti-diabetic drugs were always available at private facilities, while $11 \%$ said that the drugs were seldom available. In public facilities $52 \%$ of patients said that the drugs are always available, $41 \%$ said they were seldom available and $7 \%$ said the drugs they are using are not available at all (Table 2).

Close to $90 \%$ of patients from both private and over two thirds of patients from the public facilities said they were able to pay for anti-diabetic drugs. About $26 \%$ of patients in the public facilities had problems in paying for their medications compared to $11 \%$ in the private facilities (Table 5).

\section{DISCUSSION}

This cross sectional descriptive study aimed at determining availability, cost, affordability and sources of anti-diabetic drugs in private and public health facilities in Dar es Salaam.

Generally both private and publichealthfacilities had drugs available for managing diabetic patients as described in the National Essential Drug List. However, there were differences in the variety of oral hypoglycaemic agents, with private facilities having a wider selection of drugs. Similarly human insulin was only available in private facilities.

Availability of human insulin and of more types of oral hypoglycaemic drugs in the private 
facilities is explained by free market mechanisms in the private sector and the implementation of the National Essential Drug List in the public sector based on national resources. Public health facilities receive their drugs from MSD that distributes only essential drugs and the selection of which is based on an efficacy and cost-benefit analysis. Private facilities depend on private wholesale and retail pharmacies for their supply. The selection is determined by national regulation and purchasing power of the patients.

The availability of only two types of anti-diabetic drugs in the public facilities may restrict medical choice for treating diabetics based on specific patient needs. On the other hand, the National Essential Drug List is based on best evidence and adapted to available resources of a country. Availability of a limited number of only essential drugs in the public sector allows for continuity and consistency. Availability of more types of drugs in the private sector limits access for poor patients owing to the fact that most of the drugs that are not on the essential drugs list are expensive. The selection of drugs available on the market should be based on treatment guidelines.

The mean cost of anti-diabetic drugs was significantly higher in private compared to public health facilities. The price of animal insulin in private health facilities was ten times that in public health facilities, while that of chlorpropamide was five times higher in private facilities than in public facilities. It was also found that in private facilities, the price of human insulin is higher than that of animal insulin. The mean price of human regular insulin was US\$ 36.00, which, is seven times the mean price of animal insulin in private facilities and sixty five times the mean price of animal insulin in public facilities. Other researchers have reported similar costs of insulin $(1,6)$.

This cost difference has an important impact on access to anti-diabetic drugs. The costs observed above may explain why more patients attend public health facilities compared to private facilities, and why most of the patients used animal insulin rather than human insulin.

The differences in affordability (ability to pay) may be due to differences in social and economic status of patients attending public and private health facilities. It is well documented that affordability of anti-diabetic drugs is an important determinant in the whole process of management of diabetes $(1,8$, 9). Promoting the use of animal insulin instead of human insulin in both private and public facilities can reduce the difference in affordability.

The fact that $36 \%$ of all patients declared they had problems paying for medicine reflects what other researchersstate that, although poverty is less acute in the urban area, it is still a serious problem $(10,11)$.
In conclusion, the study results showed that there is an important difference of medicine availability for management of diabetes mellitus between private and public health facilities in Dar es Salaam. Costs of anti-diabetic drugs differ significantly between public and private facilities. Inability to pay for antidiabetic drugs remains a reality for $26 \%$ and $10 \%$ of patients in public and private facilities respectively. If access is to be assured for all now and in the years to come, financing and cost of anti-diabetic drugs will have to be reassessed. Health insurance, and possibly, more rigorous price control mechanisms may be needed to enable all diabetic patients to get the medicine they need.

\section{ACKNOWLEDGEMENTS}

To the participants, the directors of private health facilities, doctors in-charge of the diabetes clinics, all pharmaceutical personnel in the health facilities and not forgetting the patients for their time. This study was funded partly by the Swiss Tropical Institute, Switzerland and the Ministry of Science and Technology Higher Education, Tanzania.

\section{REFERENCES}

1. WHO Fact Sheet No. 321: (2006) Diabetes.

2. Mc Larty, D.G., Unwin, N., Kitange, H.M. et al. Diabetes mellitus as a cause of death in sub-Saharan Africa; Result of community-based study in Tanzania. Diabetic Med. 1996; 13: 990-995.

3. Press release WHO/ 8512 November 1998: Diabetes and human right day.

4. Diabetes mellitus from wikipedia, the free encyclopedia. http://en. Wikipedia. org/wiki/ Diabetes - mellitus\# treatment_and_management.

5. WHO Fact Sheet No 236 (Revised September 2002): The cost of diabetes.

6. Brauchli, Y. How has the implementation of a diabetes project improved the care of diabetic patients in Dar es salaam, Tanzania; A thesis submitted for partial completion of the diploma in pharmacy at the University of Basel, Switzerland 2002; 33-35.

7. Chale,S.S.M. Astudy of the economic costs of diabetes mellitus in Tanzania in 1989/1990; A dissertation submitted in partial fulfillment of the requirements for the degree of Master of Medicine (MMed) in internal medicine in the University of Dar es Salaam. 1992; 25-55: 74-81.

8. Katzung, B. G. Basic and clinical pharmacology $8^{\text {th }}$ Edition 2001; 711-732.

9. Green R. J. and Harrison, N. D. Pathology and therapeutics for pharmacists -A basis for clinical pharmacy practice $2^{\text {nd }}$ Edition 2000; 526-570.

10. The United Republic of Tanzania: Interim Poverty Reduction strategy. PDF 1 - 53 www.imf.org/external/ NP/prsp/2000/tza/02/100100.pdf.

11. Evaluation of the European Commission's support to the United Republic of Tanzania (2005) 1 - 25. www. oecd.org/dataoecd/45/38/32411720.pdf. 